predisposition which might be due to a hereditary tendency of genetic origin or to sensitization at some time. 'The exciting cause might be a hurt to which the skin would have been unresponsive if the patient's reaction balance had not been upset by mental tension, shock, or a transient virus illness or a common cold. Many patients had focal sepsis, but few exhibited recognizable efflorescences.

\section{Oral Hygiene and Anaesthesia}

The discussion which followed was opened by Dr. E. W. FIsH, who said he was pleased to hear the unanimity of the speakers on the subject of focal sepsis. He reminded the meeting of the danger of dental extractions in heart disease, citing examples. He laid much emphasis on the point that eradication of apical infections did not necessarily render a mouth free from sepsis. The gingival and paradontal tissues could harbour sepsis, which on mastication might result in a transient toxaemia or bacteriaemia. He made a plea to the dental surgeons that when asked to eradicate focal sepsis they should make quite sure that no infection remained in the gingival and paradontal tissues.

Professor M. A. Rushton agreed with the assessment of dental sepsis which had been given. Two aspects of current practice, however, did not accord with present knowledge. There was inadequate provision in hospitals for the oral hygiene of patients who were to receive general anaesthetics. And, since the frequency and extent of bacteriaemia were closely related to the number of teeth extracted, the removal of very many teeth at one time from out-patients, as was still done in many dental practices, appeared most undesirable.

Several other speakers took part in the discussion.

\section{Preparations and Appliances}

\section{OPERATION ARM-REST}

Mr. David F. Thomas, F.R.C.S., orthopaedic surgeon, Scunthorpe Group of Hospitals and Lindsey County Council, writes: The most satisfactory position of the arms during operation should be that in which (1) the arms are held completely out of the way either of the surgeon or of an $x$-ray machine-for example, in internal fixation of fractures of the upper end of the femur; (2) there is no danger of traction palsy of the brachial plexus; and (3) the arms are accessible for injections or transfusions.

I have designed an operation arm-rest which, I think, fulfils these requirements. It consists of a metal base and

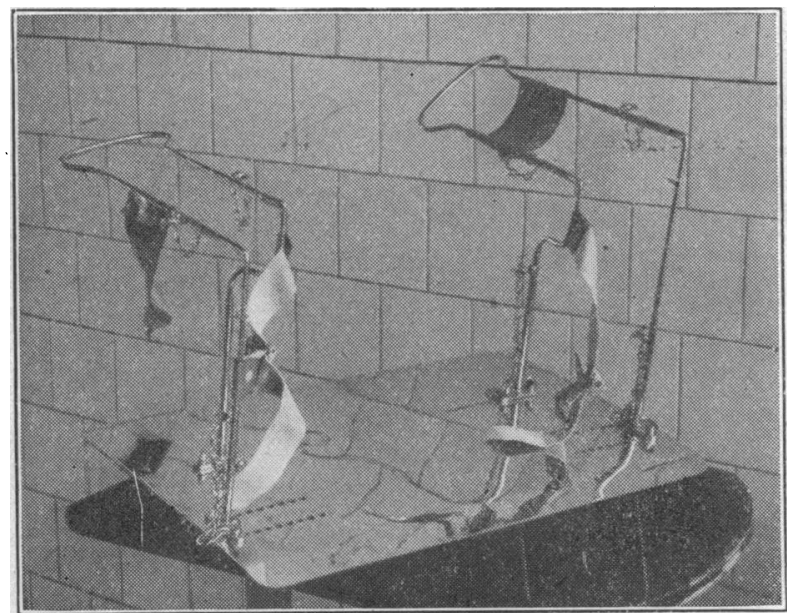

Fig. 1.-Showing especially the arrangement in the base for adjusting the distance between the arm-rests, and how the armrest can be tilted to alter the degree of pronation and supination of the forearm. two adjustable arm-rests. The arm-rests are screwed to the base, which is perforated by a series of holes to allow the distance between the arm-rests to be adjusted according to the size of the patient. Each arm-rest has a telescopic adjustment in both its vertical and its horizontal limb, and by means of this telescopic arrangement not only can the limbs be adjusted for length but the degree of pronation and supination can be altered (Fig. 1). The arms are held on the arm-rest by two simple slings-one on the horizontal portion which lies under the forearm in the region of the wrist, and one on the vertical portion which lies behind the lower part of the humerus. The slings are made not only with an adjustment for length but also with a button fastener to allow them to be undone quickly. The apparatus holds the arms in a position of rest, with adduction and flexion of the shoulder. It is a position which closely corresponds to that in which, when seated at a table, one rests the head in the hands with elbows on the table. As will be seen from Fig. 2 the arms are available to the anaesthetist for injections,

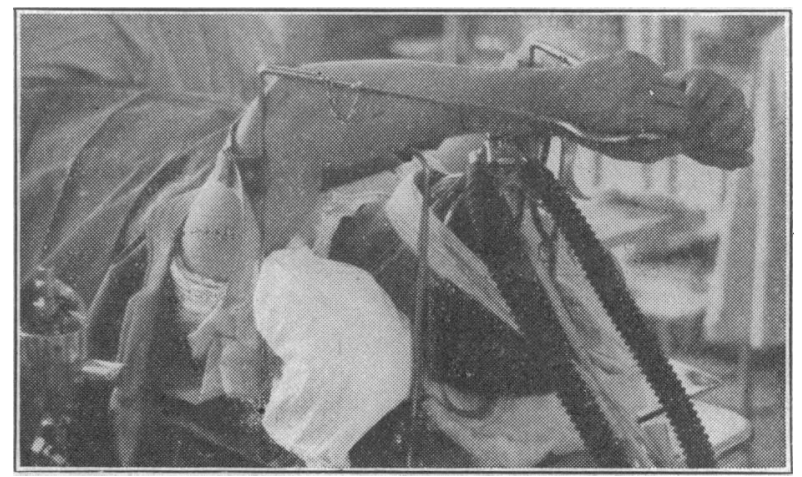

FIG. 2.-Showing the apparatus in place, as seen by the anaesthetist.

and the whole of the area of the arms and head can be sealed off from the operation field by a sterile towel.

This apparatus has been made for me by Messrs. Kempner, of Leeds, and I am grateful to Mr. Humphrey of that firm for his co-operation.

The Very Rev. Dr. John Flynn, for 40 years superintendent of the Australian Inland Mission, died on May 5 (J. Amer. med. Ass., June 16, p. 669). Between 1912 and 1928 he established 13 small hospitals, each staffed by two trained nurses, and in May, 1928, introduced the first "flying doctor," who began his work in West Queensland. He covered an area larger than the whole of France. Two years earlier Alfred Traeger, an electrical engineer, had designed a small wireless set which received and transmitted both voice and Morse; the operator generated power for this by riding a fixed bicycle, the back wheel of which drove a generator, and a typewriter keyboard was designed which automatically sent out the message in code. While he pedalled the operator tapped out what he had to say; the normal range is about 500 miles, but the "transceiver" has been effective over 2,000. With the help of the flying-doctor medical chest in every homestead, many common illnesses can be treated, and emergency care can be given. The flying doctors are usually given other tasks by the Government; one of the first of them, Dr. Allen Vickers, was appointed a police magistrate, protector of aborigines, and mining warden. Once he saw twelve patients in one day, did two operations, held an inquest, conducted a court case, extracted many teeth, renewed five hotel licences, and issued permits for native labour. A dislocated shoulder was manipulated by instructions given by wireless, the doctor and patient being 400 miles apart. In 1940 McGill University recognized John Flynn's services by conferring on him the honour of doctor of divinity; seven years previously he received the O.B.E. 